\title{
Digital 3D reconstruction of two parahissian accessory bundles in a case of Wolff-Parkinson-White syndrome
}

\author{
Steffen, Christian ; Schaepman, Michael ; Hardmeier, Thomas ; Schweitzer, Wolf
}

\begin{abstract}
Three-dimensional reconstruction of digitized histological serial sections of the cardiac conduction system yielded two accessory pathways in a case of a 24-day-old male infant who died after a short period of illness with ECG findings of Wolff-Parkinson-White syndrome. In infants, the differential diagnosis of possible accessory pathways connecting the AV conduction system, atrial or ventricular septum includes dispersed conduction system tissue without connecting features. This is why threedimensional reconstruction is necessary in order to refute or establish connectivity of cell groups as found in histological serial slice images
\end{abstract}

DOI: https://doi.org/10.1007/s00414-003-0417-0

Posted at the Zurich Open Repository and Archive, University of Zurich ZORA URL: https://doi.org/10.5167/uzh-156440

Journal Article

Published Version

Originally published at:

Steffen, Christian; Schaepman, Michael; Hardmeier, Thomas; Schweitzer, Wolf (2004). Digital 3D reconstruction of two parahissian accessory bundles in a case of Wolff-Parkinson-White syndrome. International journal of legal medicine, 118(2):101-105.

DOI: https://doi.org/10.1007/s00414-003-0417-0 


\section{Digital 3D reconstruction of two parahissian accessory bundles in a case of Wolff-Parkinson-White syndrome}

Received: 16 June 2003 / Accepted: 10 November 2003 / Published online: 31 January 2004

(C) Springer-Verlag 2004

\begin{abstract}
Three-dimensional reconstruction of digitized histological serial sections of the cardiac conduction system yielded two accessory pathways in a case of a 24-dayold male infant who died after a short period of illness with ECG findings of Wolff-Parkinson-White syndrome. In infants, the differential diagnosis of possible accessory pathways connecting the AV conduction system, atrial or ventricular septum includes dispersed conduction system tissue without connecting features. This is why three-dimensional reconstruction is necessary in order to refute or establish connectivity of cell groups as found in histological serial slice images.
\end{abstract}

Keywords Wolff-Parkinson-White syndrome · Electrocardiography $\cdot$ Histology $\cdot$ Reconstruction · Forensic pathology $\cdot$ Cardiac death

\section{Introduction}

Accessory bundles are involved in a range of arrhythmias and may play a significant role in the pathophysiology of natural or violent death. Even though the reported incidence of 'sudden death' among adults with known Wolff-

C. Steffen and W. Schweitzer contributed equally to this study.

\section{Steffen}

Abteilung Kardiologie, Klinik Schloss Mammern, 8265 Mammern, Switzerland

\section{Schaepman}

Remote Sensing Laboratories,

Institut für Geographie der Universität Zürich,

8057 Zürich, Switzerland

T. Hardmeier

8400 Winterthur, Switzerland

W. Schweitzer (凶)

Institut für Rechtsmedizin der Universität Zürich,

Winterthurerstrasse 190 Bau 52, 8057 Zürich, Switzerland

Tel.: +41-1-6355622, Fax: +41-1-6356851,

e-mail: shwi@irm.unizh.ch
Parkinson-White (WPW) syndrome is as low as 0.0015 per patient year [1], accessory pathways may go undiagnosed before facilitating serious arrhythmia. Torner [2] reported that out of 23 patients with WPW syndrome successfully resuscitated from VF (ventricular fibrillation), 6 patients had their first symptomatic arrhythmia ever. Morphologically, the incidence of Mahaim bundles was found to be higher in babies without a concise cause of death [3]. Accessory bundles were also implied as the cause of arrhythmia in accidental deaths [4].

Demonstration of accessory bundles depends on the proof of connectivity of conduction system tissue strands found in the atrioventricular region [5], which can be differentiated from unconnected tissue strands by examining a 3D (three-dimensional) reconstruction of such muscle cell islands for connectivity [6]. Other conduction system pathologies, such as fibrosis [7], calcium deposits or fatty infiltration of conduction system structures [8], can be recognized without a $3 \mathrm{D}$ reconstruction. We report digitally reconstructed histological findings of parahissian accessory bundles in a 24-day-old male who died after a short period of illness and was diagnosed with probable WPW syndrome based on post-resuscitation ECG (electrocardiogram) results.

\section{Case history}

A 24-day-old male infant died on April 28th 1980. 6 days prior to death the symptoms were thin stool and poor fluid intake. 2 days prior to death, cool skin and some vomiting were detected and 1 day prior, palpitations occurred. On what eventually was the last day, he was apathetic, sweating, and tachycardic. The general practitioner admitted the child to the University Hospital of Zurich. The infant arrived in an unconscious state with fixed and dilated pupils, without heart action, and without signs of dehydration.

Resuscitation attempts resulted in regular cardiac action and peripheral pulse after $10 \mathrm{~min}$. ECG then showed a PQ-time of $0.09-0.10 \mathrm{~s}$ (normal [9], possibly shortened but not diagnostic in infants under 12 months [10]) and a QRS width of $0.09 \mathrm{~s}$ (increased [9]). A $\Delta$-wave was most markedly noticeable in V1 and V2, and there was a left anterior hemiblock. Heart rate alternated between normal and tachycardic (over $200 \mathrm{bpm}$ ) with broad complexes. After an electroencephalogram produced a flat line, life support was turned off $10 \mathrm{~h}$ after admission to hospital. 
Fig. 1a-d Reconstruction of atriofascicular pathway (apl). a The diagram shows the position of the $3 \mathrm{D}$ reconstruction of serial sections (yellow, as seen in Fig. 1b) in relation to the atrioventricular part of the conduction system ( $A V N$ atrioventricular node, $H$ His bundle, $\varnothing$ cross section through His bundle, $R B B$ right bundle branch, $L B B$ left bundle branch, apl atriofascicular pathway, ap2 fasciculoventricular pathway). b Digital 3D reconstruction of serial sections easily discerns accessory pathway connecting atrium with His bundle (arrowheads) from non-connecting tissue strands (one of them labeled as $n c$ ). c, d Histological serial sections of the atrioventricular part of the cardiac conduction system containing the His bundle $(H)$ with conduction system tissue dispersed throughout the fibrous body contributing to atriofascicular bundle (arrowheads). $A S$ atrial septum, $V S$ ventricular septum, scale bar $1 \mathrm{~mm}$

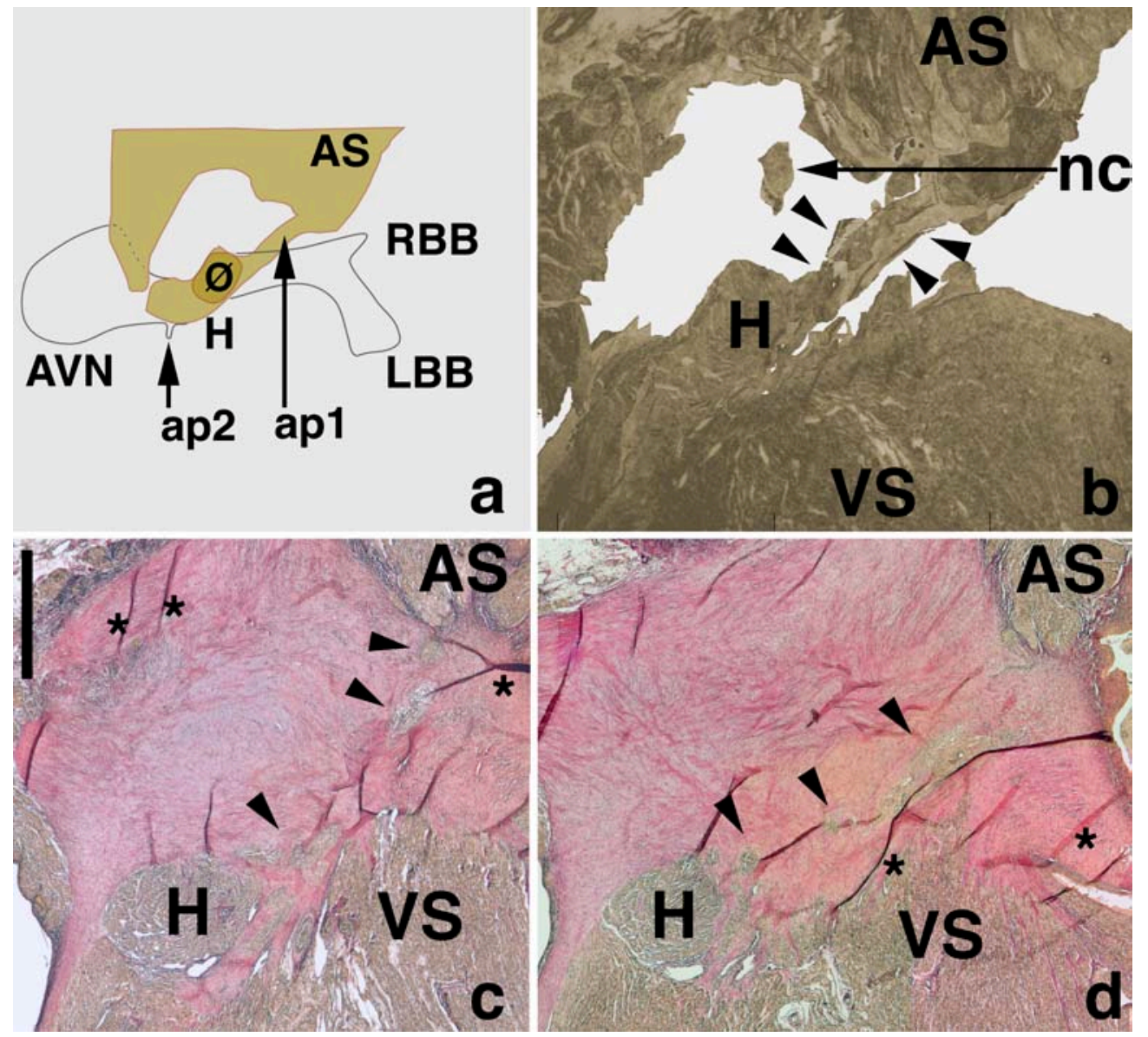

The boy had been a second-born with a birth weight of $3650 \mathrm{~g}$ $(\sim 90 \%)$ after a regular pregnancy of a healthy mother. He had received light therapy due to hyperbilirubinemia on days 5 and 6 and initial development was normal. The family history did not contain any instances of relatives succumbing to sudden death or cardiac arrhythmia. The archived patient's history did not contain ECG curve prints.

Autopsy findings did not show congenital malformations and were not conclusive as to the cause of death. Total body weight was $4100 \mathrm{~g}$ (50-75\% normal), body length was $58 \mathrm{~cm}(97 \%)$, and head circumference measured $37.5 \mathrm{~cm}(50-75 \%)$. With the exception of the thymus $(18.7 \mathrm{~g}$, normal $6.6 \pm 4.9 \mathrm{~g})$, organ weights were normal [11].

\section{Material and methods}

The posterior, lateral and septal atrioventricular junction was processed into a set of 1,300 histological serial sections spaced $50 \mu$ and stained with van Gieson-elastin stain. Histological serial sections showed cell nests or cell strands possibly contributing to accessory bundles (Figs. 1c,d and 2c,d, arrowheads) that were located over a range of 25 serial sections around the His bundle (Figs. 1 and $2 H$ ). No other signs of pathology were identified.

These 25 serial sections and a scale slide were digitized using a microscope-mounted camera (Jenoptik, Eching, Muenchen, Germany). The image series was manually co-registered into a three-dimensional data volume [12] using the first image as reference and manually positioning subsequent images through rotation and shifting. Embedding of cut tissue caused minor tissue folds (Fig. 1c,d, labeled '*') measuring around 5-10 $\mu$ in width, evenly distributed throughout the fibrous body. The co-registration error of the image series could not be measured directly, so control points were placed manually onto a number of anatomic structures with a known coherence in the z-axis (such as endocardial surface or vessels). Control point tracking yielded an in-plane deviation of 5-15 $\mu$, which we judged to be sufficiently small in order to examine structures in the $100-150 \mu$ size range.

Myocardial tissue was segmented manually from fibrous tissue in each digital image employing slice-wise validation against microscopy. Volume rendering in IDL (Interactive Data Language, Research Systems, Boulder, Colorado) resulted in three-dimensional reconstructions that were clipped in order to expose identified accessory pathways individually (Figs. $1 \mathrm{~b}$ and $2 \mathrm{~b}$ ).

\section{Results}

Visual inspection of the 3D reconstructions resulted in the identification of two accessory pathways with a parahissian location in the posterior atrioventricular septum.

One accessory pathway was an atriofascicular bundle (anatomically termed 'James' bundle [13], functionally termed Mahaim bundle [14], Fig. 1b, arrowheads) connecting the posterior atrial septum (Fig. 1b, $A S$ ) with the His bundle (Fig. $1 \mathrm{~b}, H$ ) with a smallest diameter of $100 \mu$. Dispersed or non-connecting conduction system tissue was identified in various locations (labeled $n c$ in Fig. 1b and 2b).

A second accessory bundle was a fasciculoventricular bundle (anatomically and functionally termed Mahaim 
Fig. 2a-d Reconstruction of fasciculoventricular pathway (ap2). a Diagram showing position of the $3 \mathrm{D}$ reconstruction of serial sections (yellow, as seen in Fig. 2b) in relation to the atrioventricular part of the conduction system ( $A V N$ atrioventricular node, $H$ His bundle, $\varnothing$ cross section through His bundle, $R B B$ right bundle branch, $L B B$ left bundle branch, apl atriofascicular pathway, ap2 fasciculoventricular pathway). b Digital 3D reconstruction of serial sections differentiates accessory pathway connecting His bundle with ventricle (arrowheads) from nonconnecting tissue strands (one of them labeled as $n c$ ). c, d Histological serial sections of the atrioventricular part of the cardiac conduction system containing the His bundle $(H)$ with conduction system tissue dispersed throughout the fibrous body contributing to fasciculoventricular bundle (arrowheads). AS atrial septum, $V S$ ventricular septum, scale bar $1 \mathrm{~mm}$
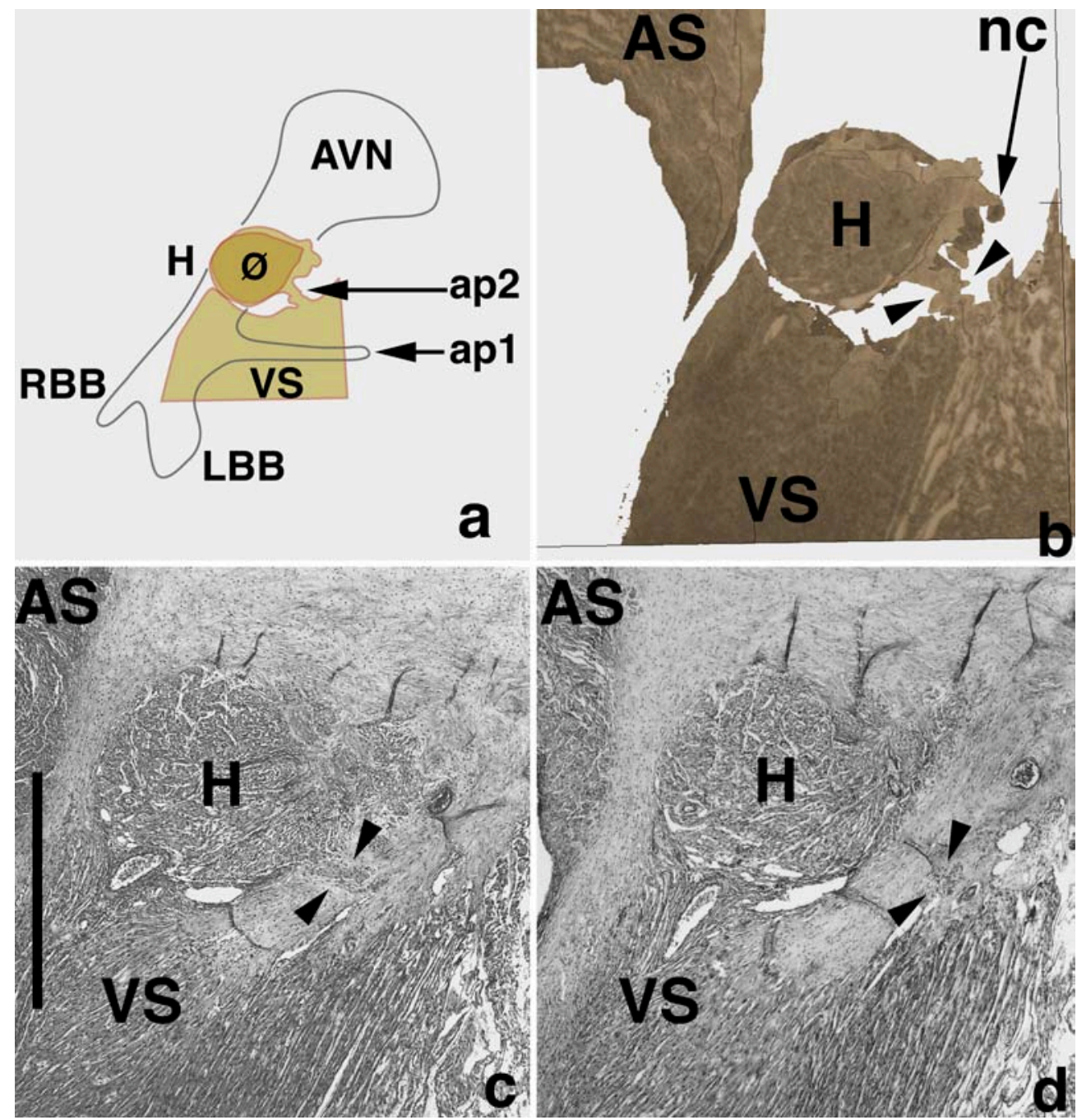

bundle [13], about $125 \mu$ diameter, Fig. 2b, arrowheads) that connected the penetrating bundle of His (Fig. 2b, $H$ ) with the ventricular septum (Fig. 2b,VS).

\section{Discussion}

WPW is a diagnosis based on ECG features from which localization of accessory pathways can be inferred. In this instance, observed $\Delta$-wave features are more likely to be based on a septal or parahissian than a parietal location of accessory pathways $[15,16]$. Broad QRS complexes suggest an antidromic circus movement tachycardia, which correlates with a higher likelihood of multiple than single accessory pathways [17]. A $\Delta$-wave is a qualitative ECG feature that reliably indicates preexcitation, whereas PQtime should be interpreted with caution since cardiac anoxia could increase the PQ-interval [18] and administration of adrenalin could shorten it. In our case, the presence of a normal rather than a shortened PQ-time suggests a fasciculoventricular rather than a nodoventricular accessory bundle [19]. Functional left bundle branch blocks are typ- ical in WPW [20] but no morphological correlate was found in this case.

We identified two parahissian accessory pathways, an atriofascicular and a fasciculoventricular pathway. Multiple pathways are associated with a higher risk of VF than single pathways [21], particularly when located in the posterior septum such as in this instance. They are found in 9\% of pediatric patients with WPW syndrome [22]. However, ECG or electrophysiological testing do not necessarily diagnose any of the accessory pathways present, particularly in metabolically well-balanced individuals, where such pathways may remain silent for many years. As WPW may run in families in an autosomal dominant way [23], establishing a correct diagnosis at autopsy could help identifying risk groups before first symptoms manifest themselves as serious or lethal arrhythmia in surviving relatives.

Anatomically receding accessory pathways were suggested to be a temporary complication of cardiac development [5], which would explain why arrhythmia commonly associated with accessory pathways in newborns has been observed to resolve spontaneously within a year [24]. In 
this male infant, death was preceded by a mild illness over several days: mild diarrhea, vomiting, and poor fluid intake without notable dehydration probably triggered reentry tachycardia and atrial fibrillation on the basis of activated accessory pathways.

Whenever death in previously asymptomatic carriers of a peculiarity, such as accessory bundles, but including others, is precipitated through dehydration [25], changes in diet [20], exercise [26], restraint [27], hypokalemia [28], catecholamines [29], or emotional stress [30], legal categorization of the death can be controversial [31]. In this instance, absence of perceptible dehydration led to the conclusion of natural death as a consequence of WPW syndrome. There was no prior indication that mild dehydration would have been detrimental to the child prior to death other than the palpitations the mother had noted.

In interpreting findings as to the cause and manner of death, exclusion of violence $[32,33,34]$ and toxicological factors [35] as well as elucidation of legal responsibility [36] represent crucial steps in forensic cardiac conduction system pathology particularly in infant deaths without a prior history [37]. A full medicolegal investigation into deaths as a consequence of WPW syndrome should take into account that there are diagnostic and therapeutic options, as clinical identification of accessory pathways and antiarrhythmic medication [38] or catheter ablation are routine today even in infants [39].

Full 3D assessment of connectivity of dispersed tissue in pathological anatomy of the cardiac conduction system has the potential to match clinical accuracy in diagnosing accessory pathways [40] or exceed it in the posteroseptal region and in instances of multiple pathways which can be difficult to localize electrophysiologically [41]. Therefore, the technique presented provides an essential tool for forensic conduction system pathology [42] and a relevant complement to modern cardiac investigative morphology such as the search for early vital reactions to myocardial infarction $[43,44,45,46]$.

Acknowledgements We would like to express our deep gratitude to Jakob Schneider, now at the Institute of Pathology at the University of Addis Ababa, Ethiopia, for preparing the tissue blocks and serial sections and making the tissue available for review. Work leading up to this study was supported by a grant of the Gebert Rüf Stiftung, Switzerland and by support of the Institute of Legal Medicine in Zürich to Dr. Schweitzer.

\section{References}

1. Munger TM, Packer DL, Hammill SC et al. (1993) A population study of the natural history of Wolff-Parkinson-White syndrome in Olmsted County, Minnesota, 1953-1989. Circulation $87: 866-873$

2. Torner P (1988) Ventricular fibrillation in the Wolff-Parkinson-White syndrome. Pacing Clin Electrophysiol 11:46

3. Matturri L, Ottaviani G, Ramos SG, Rossi L (2000) Sudden infant death syndrome (SIDS): a study of cardiac conduction system. Cardiovasc Pathol 9:137-145

4. Nishida N, Ikeda N, Kudo K, Tsuji A, Kiyoshima A (2002) Forensic significance of conduction system abnormalities as a precise cause of accidental death. Int J Legal Med 116:344-349
5. James TN (1970) Cardiac conduction system: fetal and postnatal development. Am J Cardiol 25:213-226

6. Schweitzer W, Maass D, Schaepman M, Wagen M, Ranson D, Hardmeier T (1998) Digital 3D image reconstruction of ventriculocapillary communication as revealed in one case after transmyocardial laser revascularization. Pathol Res Pract 194: $65-71$

7. Piercecchi-Marti MD, Mohamed H, Chau C, Liprandi A, Fredouille C (2003) Congenital atrioventricular block: histological aspects. Forensic Sci Int 136:12-15

8. Song Y, Laaksonen H, Saukko P, Toivonen S, Zhu J (2001) Histopathological findings of cardiac conduction system of 150 Finns. Forensic Sci Int 119:310-317

9. Davignon A, Rautaharju P, Boisselle E, Soumis F, Megelas M, Choquette A (1979) Normal ECG standards for infants and children. Pediatr Cardiol 1:123-131

10. Perry JC, Giuffre RM, Garson A Jr (1990) Clues to the electrocardiographic diagnosis of subtle Wolff-Parkinson-White syndrome in children. J Pediatr 117:871-875

11. Schulz DM, Giordano DA, Schulz DH (1962) Weights of organs of fetuses and infants. Arch Pathol 74:244-264

12. Brey EM, King TW, Johnston C, McIntire LV, Reece GP, Patrick CW Jr (2002) A technique for quantitative three-dimensional analysis of microvascular structure. Microvasc Res 63:279-294

13. Anderson RH, Becker AE, Brechenmacher C, Davies MJ, Rossi L (1975) Ventricular preexcitation. A proposed nomenclature for its substrates. Eur J Cardiol 3:27-36

14. Haissaguerre M, Cauchemez B, Marcus F et al. (1995) Characteristics of the ventricular insertion sites of accessory pathways with anterograde decremental conduction properties. Circulation 91:1077-1085

15. Haissaguerre M, Marcus F, Poquet F, Gencel L, Le Metayer P, Clementy J (1994) Electrocardiographic characteristics and catheter ablation of parahissian accessory pathways. Circulation 90:1124-1128

16. Arruda MS, McClelland JH, Wang X et al. (1998) Development and validation of an ECG algorithm for identifying accessory pathway ablation site in Wolff-Parkinson-White syndrome. J Cardiovasc Electrophysiol 9:2-12

17. Wellens HJ, Atie J, Penn OC, Gorgels AP, Brugada P, Smeets JL (1990) Diagnosis and treatment of patients with accessory pathways. Cardiol Clin 8:503-521

18. Rey de Vinas JL, Ruiz F, Lucas-Gallego J (1978) Interrelaciones electrolíticas y electrocardiográficas bajo la acción de un 7\% de O2 en N2 (in Spanish). Rev Esp Fisiol 34:379-383

19. Gallagher JJ, Smith WM, Kasell JH, Benson DW Jr, Sterba R, Grant AO (1981) Role of Mahaim fibers in cardiac arrhythmias in man. Circulation 64:176-189

20. Wolff L, Parkinson J, White P (1930) Bundle branch block with short P-R interval in healthy young people prone to paroxysmal tachycardia. Am Heart J 5:685

21. Attoyan C, Haissaguerre M, Dartigues JF, Le Metayer P, Warin JF, Clementy J (1994) La fibrillation ventriculaire dans le syndrome de Wolff-Parkinson-White - facteurs prédictifs. Arch Mal Coeur Vaiss 87:889-897

22. Weng KP, Wolff GS, Young ML (2003) Multiple accessory pathways in pediatric patients with Wolff-Parkinson-White syndrome. Am J Cardiol 91:1178-1183

23. Liu W, Liu G, Hu D, Qi Y, Shan Z, Yang D, Liu D, Wang Y (2002) Familial Wolff-Parkinson-White syndrome is linked to the loci on chromosome 7q3. Chin Med J (Engl) 115:17331735

24. Seletti L, Squarcia U (1987) Le aritmie cardiache nell'infanzia (in Italian). Pediatr Med Chir 9:537-541

25. Wirthwein DP, Spotswood SD, Barnard JJ, Prahlow JA (2001) Death due to microvascular occlusion in sickle-cell trait following physical exertion. J Forensic Sci 46:399-401

26. Byard RW, James RA, Gilbert JD (2002) Childhood sporting deaths. Am J Forensic Med Pathol 23:364-367 
27. Roeggla M, Wagner A, Muellner M, Bur A, Roeggla H, Hirschl MM, Laggner AN, Roeggla G (1997) Cardiorespiratory consequences to hobble restraint. Wien Klin Wochenschr 109:359-361

28. Chait L, Mandel WJ (1973) Wolff-Parkinson-White syndrome: alterations in ventricular activation induced by changes in serum potassium. Chest 64:780-781

29. Weismuller P, Thamasett S, Grossmann G, Wierse G, Hombach V (1996) Demaskierung einer ausschliesslich retrograd leitenden akzessorischen Bahn durch Katecholamine. Z Kardiol 85:949_ 952

30. Timmermans C, Smeets JL, Rodriguez LM, Vrouchos G, Dool A van den, Wellens HJ (1995) Aborted sudden death in the Wolff-Parkinson-White syndrome. Am J Cardiol 76:492-494

31. Cordner S (2003) Suicide, accident, murder or natural death. In: Payne-James J, Smock W, Busuttil A (eds) Forensic medicine: clinical and pathological aspects. GMM, San Francisco, London, pp 133-147

32. Klotzbach H, Delling G, Richter E, Sperhake J, Püschel K (2003) Post-mortem diagnosis and age estimation of infants' fractures. Int J Legal Med 117:82-89

33. Darok M, Beham-Schmid C, Gatternig R, Poll P (2001) Sudden death from myocardial contusion following an isolated blunt force trauma to the chest. Int J Legal Med 115:85-89

34. Banaschak S, Schmidt P, Madea B (2003) Smothering of children older than 1 year of age - diagnostic significance of morphological findings. Forensic Sci Int 134:163-168

35. Bajanowski T, Fürst $P$, Wilmers K, Beike J, Köhler H, Brinkmann B (2002) Dioxin in infants - an environmental hazard? Int J Legal Med 116:27-32

36. Fechner G, Du Chesne A, Ortmann C, Brinkmann B (2002) Death due to intravenous application of enteral feed. Int $\mathrm{J}$ Legal Med 116:354-356
37. Bajanowski T, Ortmann C, Teige K, Wedekind H, Zack F, Röse I, Brinkmann B (2003) Pathological changes of the heart in sudden infant death. Int J Legal Med 117:193-203

38. Pfammatter JP, Stocker FP (1998) Re-entrant supraventricular tachycardia in infancy: current role of prophylactic digoxin treatment. Eur J Pediatr 157:101-106

39. Blaufox AD, Felix GL, Saul JP (2001) Radiofrequency catheter ablation in infants $\leq 18$ months old: when is it done and how do they fare? Short-term data from the pediatric ablation registry. Circulation 104:2803-2808

40. Boersma L, Garcia-Moran E, Mont L, Brugada J (2002) Accessory pathway localization by QRS polarity in children with Wolff-Parkinson-White syndrome. J Cardiovasc Electrophysiol 13:1222-1226

41. Teo WS, Klein GJ, Guiraudon GM, Yee R, Leitch JW (1991) Predictive accuracy of electrophysiologic localization of accessory pathways. J Am Coll Cardiol 18:527-531

42. Gulino SP (2003) Examination of the cardiac conduction system: forensic application in cases of sudden cardiac death. Am J Forensic Med Pathol 24:227-238

43. Baroldi G, Mittleman RE, Parolini M, Silver MD, Fineschi V (2001) Myocardial contraction bands. Definition, quantification and significance in forensic pathology. Int J Legal Med 115:142-151

44. Edston E, Grontoft L, Johnsson J (2002) TUNEL: a useful screening method in sudden cardiac death. Int $\mathrm{J}$ Legal Med 116:22-26

45. Nakatome M, Matoba R, Ogura Y et al. (2002) Detection of cardiomyocyte apoptosis in forensic autopsy cases. Int J Legal Med 116:17-21

46. Ortmann C, Pfeiffer H, Brinkmann B (2000) A comparative study on the immunohistochemical detection of early myocardial damage. Int J Legal Med 113:215-220 